Fall 9-2-2020

\title{
Understanding the Impact of Social Distancing on Older Adults and Senior Centers to Better Adapt Towards a New Normal
}

Salina Jivan

University of St. Augustine for Health Sciences

DOI: https://doi.org/10.46409/sr.MHRK5885

Follow this and additional works at: https://soar.usa.edu/capstones

Part of the Geriatrics Commons, and the Occupational Therapy Commons

\section{Recommended Citation}

Jivan, S. (2020). Understanding the Impact of Social Distancing on Older Adults and Senior Centers to Better Adapt Towards a New Normal. [Doctoral project, University of St Augustine for Health Sciences]. SOAR @ USA: Student Capstone Projects Collection. https://doi.org/10.46409/sr.MHRK5885

This Capstone is brought to you for free and open access by the Student Research at SOAR @ USA. It has been accepted for inclusion in Student Capstone Projects by an authorized administrator of SOAR @ USA. For more information, please contact soar@usa.edu, erobinson@usa.edu. 


\title{
Understanding the Impact of Social Distancing on Older Adults and Senior Centers to
}

\section{Better Adapt Towards a New Normal}

\author{
Salina M Jivan, OTDS
}

Department of Occupational Therapy, University of St. Augustine for Health Sciences

Susan MacDermott, OTD, OTR/L and Becki Cohill, OTD, OTR/L

A Capstone Presented in Partial Fulfillment

of the Requirement for the Degree of

DOCTOR OF OCCUPATIONAL THERAPY

University of St. Augustine for Health Sciences

August 2020 
Understanding the Impact of Social Distancing on Older Adults and Senior Centers to

Better Adapt Towards a New Normal

\begin{abstract}
Salina M Jivan, OTDS
Department of Occupational Therapy, University of St. Augustine for Health Sciences

has been approved
\end{abstract}

August 2020

APPROVED:

Susan MacDermott, OTD, OTR/L, Doctoral Coordinator

Becki Cohill, OTD, OTR/L, Doctoral Coordinator

Erin Schwier, EdD, OTD, OTR/L, Program Director

ACCEPTED AND SIGNED:

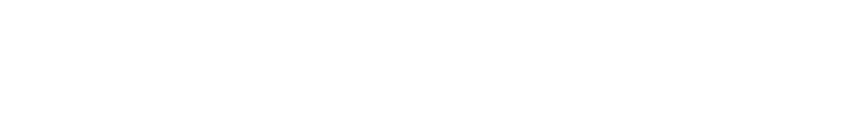

Susan MacDermott, OTD, OTR/L, Doctoral Coordinator

Becki Cohill OTD OTR/L

Becki Cohill, OTD, OTR/L, Doctoral Coordinator

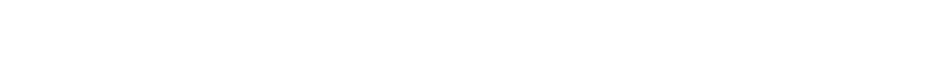

Erin Schwier, EdD, OTD, OTR/L, Program Director 


\section{Table of Contents}

Chapter 1: Introduction

Background

Statement of the Problem

Purpose Statement

Rationale for Proposed Project

Significance of the Proposed Project

Objectives

Definition of Terms

Assumptions, Limitations, and Delimitations

Chapter 2: Literature Review

Importance of Social Participation for Healthy Aging

COVID-19 and Seniors

Benefits of Senior Centers on Well-being of the Elderly

Literature Review Conclusion

Part 1: Qualitative Study

Results of Part 1: Qualitative Study 
Chapter 5: Discussion and Conclusion $\quad 34$

$\begin{array}{ll}\text { Discussion } & 34\end{array}$

$\begin{array}{ll}\text { Recommendations } & 36\end{array}$

$\begin{array}{ll}\text { Limitations } & 37\end{array}$

$\begin{array}{ll}\text { Dissemination } & 38\end{array}$

$\begin{array}{lr}\text { Conclusion } & 38\end{array}$

$\begin{array}{lr}\text { References } & 40\end{array}$

$\begin{array}{ll}\text { Appendix A : IRB Approval Letter } & 47\end{array}$

Appendix B : Senior Interview Questions $\quad 48$

Appendix C : 6 Item Cognitive Impairment Test 50

Appendix D: Senior Organization Interview Questions 52

Appendix E: Power Point Presentation for Senior Organizations 53

Appendix F: Recommendations Handout $\quad 54$

$\begin{array}{ll}\text { Appendix G: Journal Publication } & 60\end{array}$ 
Copyright (๑) Salina Jivan, 2020 all rights reserved 


\section{Acknowledgements}

Special thanks to Christine Childers, PT, BSc (Hons), MS, PhD for giving me the opportunity to join as a co-researcher on her project and being a source of support throughout this research process. I also want to give a big thanks to my mentor Kathleen Elgas OTR/L for her continued support and shared wisdom throughout this journey. 


\section{Understanding the Impact of Social Distancing on Older Adults and Senior Organizations \\ to Better Adapt Towards a New Normal \\ Chapter 1: Introduction}

The purpose of this capstone was to understand the impact of social distancing on older adults and senior organizations to better adapt towards a new normal during the COVID-19 pandemic.

\section{Background}

The lifespan of the average American adult has increased over the past few decades. The Healthy People 2020 Initiative projected that the population over the age of 65 would increase from 46.3 million in 2014 to 98 million by 2060 (Office of Disease Prevention and Health Promotion, 2014). A growing number of older adults wish to age in place within their community (Leland \& Elliot, 2012). Due to their growing population, access to supportive environments for social participation within the community is essential to older adult's wellbeing (Turcotte et al., 2018). Community organizations such as senior centers offer a variety of recreational and social networking opportunities to local communities (Dattilo et al., 2015).

Aging brings about various changes in social, physical health, and psychological health that can have an impact on quality of life (Stav et. al., 2012). The risk for social isolation increases as people age due to factors such as losing loved ones, health problems, and living alone (Centers for Disease Control [CDC], 2020a). Older adults who feel socially isolated increase their risk for cognitive decline, depression, and premature death (National Institute of Health, 2019). A sense of community and ability to engage in meaningful social participation later in life have positive health benefits. A study on the world's Blue Zones, which are areas 
known for increased longevity, happiness, and wellbeing, found residents had lower levels of depression due to more engagement in leisure and social participation (Hitchcott et al., 2018). Leisure and social participation within the community also contribute to an individual's autonomy, self-determination, and quality of life (Dattilo et al., 2015).

A person's ability to engage in meaningful social participation later in life can be affected by changes in client factors, performance patterns, context and environment (American Occupational Therapy Association [AOTA], 2014). Life transitions into retirement and older adulthood can also bring about changes in roles and routines. Improving social participation throughout the lifespan is a topic in which occupational therapy (OT) is well versed in. Occupational therapists understand and recognize the transitions throughout a person's lifespan and how they impact that person's occupational performance in their daily activities.

Prior to the COVID-19 pandemic the focus of this capstone was to understand the barriers to social participation at senior centers among the community dwelling elderly to help prevent social isolation. Many factors were considered when exploring barriers to senior center participation including: stigma, cultural, chronic illness, psychosocial, transportation, financial reasons, and other social outlets. However, an unforeseen barrier to community social participation overshadowed these previous concerns.

At the beginning of 2020, the world was faced with the threat of a fast spreading virus called COVID-19 that led to a global pandemic. By March 2020, many states within America began shutting down non-essential businesses and enforcing shelter in place mandates to reduce the spread. Adults 65 years and older are at a higher risk for severe illness from the virus, especially those with underlying health conditions (CDC, 2020b). COVID-19 can lead to complications and sometimes even death. Within the United States, 8 out 10 reported deaths 
were older adults (CDC, 2020b, graphic \#1). With the virus becoming a new barrier to meaningful social participation in the community, the risk for social isolation took on a new importance. Naturally, the focus of the project shifted to better understand the impact of social distancing on older adults and senior organizations during this time.

\section{Statement of the Problem}

Social distancing mandates around the country can have a detrimental effect to older adults' autonomy and quality of life over a longer period of time (Plagg, 2020). With COVID-19 threatening millions of lives, organizations that supported community dwelling seniors have been required to close in person services. The long-term physical, emotional, and psychosocial effects of COVID-19 are not known at this time, and it important to understand how occupational therapy can help support the recovery of seniors post-pandemic.

\section{Purpose Statement}

The purpose of this project was to understand the impact of social distancing on older adults and senior organizations to better inform the role of OT in helping seniors adapt towards a new normal within the community.

\section{Rationale for Proposed Project}

The Person-Environment-Occupation-Performance Model (PEOP) is based on the idea that participation is affected by various aspects of the environment: built, natural, cultural, social and economic systems (Christiansen \& Baum, 2005). This model helps identify extrinsic and intrinsic barriers to occupational engagement. COVID-19 has become an extrinsic barrier to social participation within the community for older adults. Social distancing and shelter in place mandates put restrictions on older adults' occupational performance, which can lead to dysfunction (Christiansen et al., 2005). The PEOP Model can help practitioners understand how 
COVID-19 has changed our social and built environments and its effect on well-being of community dwelling adults.

The Model of Human Occupation (MOHO) explains how personal volition or motivation is essential for participation in occupation (Kielhofner, 2002). This model recognizes that a person is an open system whose occupational performance is influenced by volition, habituation and mind-brain-body performance (Cole \& Tufano, 2008, p.97). MOHO states the environment can have an impact on a person's internal motivation (Cole \& Tufano, 2008, p.96). COVID-19 can reduce motivation to participate in meaningful occupations due to fear of becoming ill.

\section{Significance of the Proposed Project}

Social distancing mandates throughout the country have put a strain on older adult's social participation within the community. Although social distancing benefits the safety of seniors, prolonged loss of social contact increases risk for social isolation and loneliness (Van Orden, et. al, 2020). The long- term effects of this pandemic on the well-being of seniors are unknown. Understanding the impact of social distancing on older adults will benefit senior organizations by providing insight for future programming. The experiences of organizations that support seniors can help inform occupational therapy's role in senior reintegration back into the community once social distancing mandates are lifted.

\section{Objectives}

\section{Learning Objectives}

I. Gain insight into current senior virtual programming for social participation through online research.

II. Assess community resources that support senior's wellbeing during social distancing through online research. 
III. Understand the lived experiences of older adults during social distancing via phone and video interviews through conducting a qualitative study.

IV. Understand the experiences and challenges of community foundations/ organizations that support seniors, during the COVID-19 pandemic via phone interviews.

\section{Outcome Objectives}

I. To share the lived experiences of older adults during social distancing with organizations that support seniors.

II. To develop detailed recommendations for senior centers to help support senior reintegration into community when social distancing restrictions are no longer necessary.

III. To develop recommendations for enhancing social participation while using virtual programs for those who do not feel comfortable returning to the community.

IV. To inform occupational therapy practitioners on how to help seniors adapt to a new normal and support well-being.

\section{Definition of Terms}

Community dwelling elderly within this project are adults who are 65 years and older living independently within the community.

Community based senior centers serve the community and support aging through offering services related health and wellness, nutrition, arts, and volunteer opportunities (All about seniors, 2017). 
COVID-19 is a new strain of coronavirus that causes respiratory illness and is spread from person to person via droplets in the air (John Hopkins Medicine, 2020).

Social distancing is a preventative action intended to prevent the spread of infectious diseases by maintaining a minimum of 6 feet of physical distance from others (CDC, 2020c).

Social isolation refers to having less social contact and relationships with others (National Academies of Sciences, Engineering, and Medicine, 2020).

Social participation is defined as engagement of occupations or activities that occur socially (AOTA, 2014).

Well-being is defined by the CDC as the positive overall health of a person (CDC, 2018, para. 4). Well-being includes the following elements that contribute to overall life satisfaction: physical, social, psychological and emotional health (CDC, 2018, para. 4).

\section{Assumptions, Limitations, and Delimitations}

The premise of this capstone was based on a few assumptions. One assumption was that social distancing mandates and senior organization closures would continue to be present throughout the duration of the project. The numbers of positive COVID-19 cases continued to rise daily in the U.S throughout the month of May when the interviews were being conducted (Wikipedia, 2020). This was a strong indicator that both social distancing mandates and senior organization closures would stay in effect throughout the end of the year.

One limitation was the willingness of seniors and senior organizations to participate in phone interviews during this stressful time. Another limitation was time, due to the unpredictable nature of COVID-19 the new project focus was initiated a few months before graduation.

Delimitations included use of convenience sampling to recruit senior participants and organizations. Due to the limited time frame to complete the project and shelter in place orders, 
convenience sampling was used to gain a larger pool of participants. A second delimitation was the criteria that seniors must be independent community dwelling seniors. The focus was put on independently living seniors due to better understand how to support older adults who wish to age in place.

\section{Chapter 2: Literature Review}

A review of the literature was conducted to identify supports for wellbeing of older adults as well as new findings on how COVID-19 had impacted seniors around the world. The following themes emerged: importance of social participation for healthy aging, COVID-19 and seniors, and benefits of senior centers on wellbeing of seniors.

\section{Importance of Social Participation for Healthy Aging}

The literature supported that social participation contributed to overall well-being. Social participation led to social networking which added to a sense of belonging (Ashida \& Heaney, 2008). Loneliness could lead to depression and cognitive decline (Nedelcu, 2018). The presence

of social relationships and belonging within a person's life could positively impact their ability to deal with stressful life events (Nedelcu, 2018). Elderly individuals who had an active social life reported higher quality of life and were at less risk for depression (Wanchai \& Phrompayak, 2019). A three-year longitudinal study conducted on community dwelling Japanese seniors found that participation in one to two social organizations reduced the risk for social isolation (Ejiri et al., 2019). Social participation could also contribute to occupational performance. Increased social engagement within the community reduced the risk of poor instrumental activity of daily living performance (Tomioka et al., 2017).

Most of the literature regarding the importance of social participation for healthy aging does not limit its use to senior centers. Volunteering amongst older adults was found to provide a 
sense of purpose late in life and to improve well-being (Cattan et al., 2011). Smallfield and Molitor (2018) conducted a systematic review of various OT intervention that supported social participation for community dwelling older adults. The authors found that OT enhanced social participation in adults with chronic health conditions through education.

\section{COVID-19 and Seniors}

Due to COVID-19 being a novel virus, knowledge on its impact and related supportive occupational therapy intervention for older adults is limited. There were, however, several articles that discuss the concern for decline in overall health of seniors and the importance of taking preventative action early on. An article published in Physical \& Occupational Therapy in Geriatrics supports the need for physical therapy (PT) and OT in helping seniors recover from the adverse health and lifestyle effects of COVID-19 (Viera et al., 2020). The same article goes on to point out that both rehab specialties require expansion of their telehealth delivery models (Viera et al., 2020). Progression towards telehealth and home-based programs to support resilience and recovery from future pandemics were also encouraged within another article (Chen, 2020). The importance of continued health promotion of seniors to prevent functional decline and falls via online home exercise programs, was supported by a study in Tokyo (Aung et al., 2020). Health anxiety, financial worry and loneliness were other impacts felt by older adults within a study looking at the psychological outcomes of the pandemic (Tull et al., 2020).

\section{Benefits of Senior Centers on Well-being of the Elderly}

The literature supported that senior centers had a positive impact on the well-being of the elderly. Older adults faced the risk of social isolation as a result of decreased social participation and decline in health (Dattilo et al, 2015). A study by Campbell and Aday (2001), found senior centers could serve as a community-based site for health promotional programs targeting chronic 
illnesses. There are several ways programming could be used to improve quality of life. For example, they could specifically address public health issues. Noel et al (2016) found that elderly individuals with lower socioeconomic status, with prediabetes, and type two diabetes benefitted from their primary care physicians' recommendation to participate at a local senior center. Physical activity offered through various exercise programs served as a great resource for preventative health (Noel et al, 2016). Fall prevention could be addressed through evidencebased programs at senior centers. The findings of Li et al (2016) supported this idea, as they achieved a $49 \%$ reduction in falls by implementing Tai Ji Quan: Moving for Better Balance (TJQMBB) at senior centers in Oregon.

Participation in leisure activities has also been shown to maintain mental and physical health throughout the aging process through leisure (Fitzpatrick et al, 2006). Rosenbaum et al (2014) suggested that senior centers could be restorative by offering seniors an escape from everyday life through "adult-oriented play" and social connections (p.369). Overall, healthy aging within the community can be supported through various activities and programs offered at senior centers.

\section{Conclusion}

After completing the literature review it is apparent that social participation later in life adds to quality of life. Senior centers also support well-being of community dwelling seniors through health promotion, social opportunities, and leisure. There are gaps in the literature regarding COVID-19 related occupational therapy interventions for seniors at this time. However, new literature is being published around COVID-19 daily. Therefore as more knowledge is understood around the effects of this pandemic on older adults, solutions can be derived. 


\section{Chapter 3: Project Description}

This project included an IRB approved qualitative study (see appendix A) and a needs assessment. The purpose of the study was to understand the experiences of social distancing on older adults' lives. At the end of April 2020, the amended IRB proposal was approved to include the OT student as a co-investigator on Dr. Childers' study. Senior interviews and outreach began at the start of May 2020 and were completed at the end of the month. The purpose of the needs assessment was to understand the challenges senior organizations faced during the pandemic. Senior center interviews and outreach were conducted throughout June 2020.

\section{Part 1: Qualitative Study}

This portion of the capstone was a part of a qualitative IRB study that was conducted in collaboration (co-researcher) with Dr. Christine Childers, PT, BSc (Hons), MS, PhD. This study was approved by the University of St. Augustine for Health Sciences Institutional Review Board, San Marcos, Campus on April 30th, 2020. The semi-structured interview questions were adapted to capture a holistic understanding of older adult's experiences during the COVID-19 pandemic (see Appendix B). Qualitative open-ended questions were used to allow participants to share their personal opinions (Creswell, 2014). Participants within the study were recruited by convenience sampling through email outreach due to limited time frame to complete interviews before social distancing mandates were removed. Criteria for eligibility included: being 65 years or older; living independently within the community; and passing a six-item screening for cognitive impairment (see Appendix C). Participation was open to all ethnicities, genders, and socioeconomic status to include more diversity. Prior to interviews, consent was gained for participation within the study. A copy of the consent form was e-mailed to participants to review 
beforehand or verbally reviewed over the phone if the individual did not have an e-mail address. Interviews lasted approximately 20-40 minutes and were held over the phone or video call depending on participants preference. Audio content from the interviews was recorded utilizing the Voice Recording application for iPhone and safely secured by phone passcode.

\section{Part 2: Needs Assessment of Senior Organizations}

Leaders of community senior centers were interviewed as a part of a needs assessment for the capstone project. Senior organizations were emailed by convenience and random sampling to gain diverse experiences throughout the country. Semi-structured interviews were held with senior organization leaders via phone or video call for a duration of 20-30 minutes each (see Appendix D for sample questions). Prior to interview verbal consent was received from the participant to audio record the session for note-taking purposes. 


\section{Chapter 4: Results and Analysis}

\section{Results for Part 1: Qualitative Study}

\section{Demographic Overview of Senior Participants}

A total of 42 participants were recruited: 31 females and 11 males. Twelve different states were included: California $(n=18)$, Texas $(n=6)$, Florida $(n=5)$, Hawaii $(n=1)$, Kansas $(n=1)$, North Carolina $(n=1)$, New Mexico $(n=1)$, New York $(n=2)$, Ohio $(n=1)$, Oklahoma $(n=1)$, South Carolina $(n=2)$, and Tennessee $(n=1)$. Various age groups participated ranging from 65 to 93 years old. The majority of participants $(58 \%)$ were between the ages of $65-68(n=12)$ and 74-78 $(n=12)$. Only five participants did not own a smart phone. When asked to rate their loneliness score on a scale of one through ten, with ten being the loneliest, the majority of seniors rated themselves below a five.

\section{Figure 1}

Seniors Who Lived Alone Versus with Others

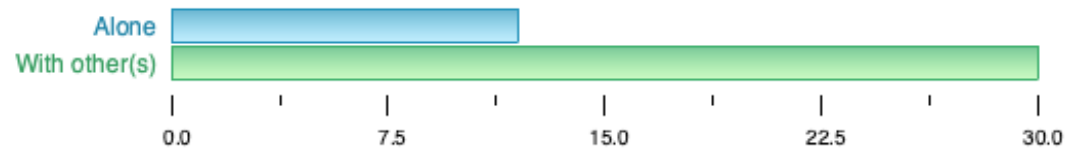

\section{Figure 2}

Age Range of Participants

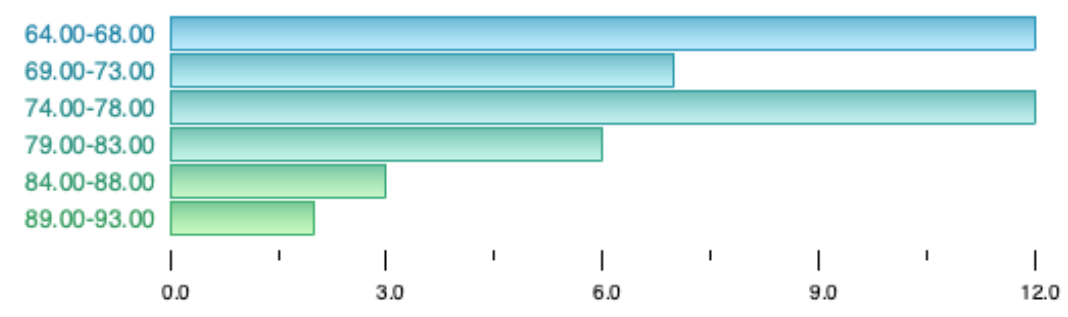




\section{Figure 3}

\section{Self-rated Loneliness Score}

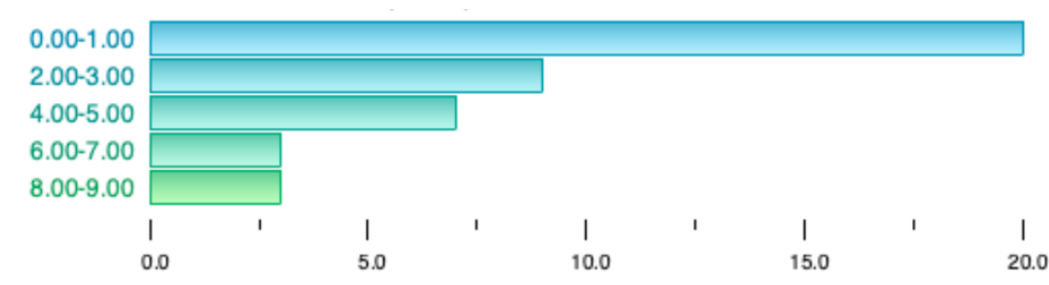

\section{Results for Part 2: Needs Assessment of Senior Organizations}

\section{Overview of Senior Organizations Interviewed}

Ten senior organizations were contacted via e-mail for interviews, from which three senior centers and two senior resource organizations agreed to share their experiences. A summary of locations and services provided by each organization is listed below.

\section{Table 1}

Senior Organization Overview

\begin{tabular}{|l|l|l|}
\hline Organization Name & Location & Services \\
\hline San Marcos Senior Center & San Marcos, CA & Recreation, Meals \\
\hline Durham Center for Senior Life & Durham, NC & Recreation, Meals \\
\hline Orange Country Senior Centers & NC & Recreation \\
\hline Foundation for Senior Wellbeing & San Marcos, CA & Resource Center \\
\hline Interfaith Community Services & San Diego County & Resource, Meals, Housing \\
\hline
\end{tabular}

\section{Analysis for Part 1: Qualitative Study}

\section{Senior Interviews}

Each participant was assigned a number, which was recorded on a master list along with their first name. Interviews were manually transcribed from audio onto a Word document and 
saved under assigned participant numbers on a password-protected personal computer.

Qualitative analysis was conducted using Braun and Clarke's framework for thematic analysis to identify over-arching themes from the data (2006). According to Braun and Clarke (2006) the six phases of thematic analysis include: 1) becoming familiar with data; 2) creating initial codes; 3) searching for themes; 4) reviewing themes; 5) defining themes; and 6) writing the report (p.35). In the second phase, 98 codes were initially identified from the 42 interview transcripts and organized via an online program called Dedoose (Braun \& Clarke, 2006). Cross-checking of codes was performed between both co-investigators to improve reliability of qualitative research approach (Gibbs, 2007). Codes were then written out on individual pieces of paper and grouped into preliminary themes. Coded excerpts were reviewed numerous times and themes were revised to ensure the overall interpretation of the data was representative of the proposed themes. Table 2 below shows what codes depicted the final themes. Peer de-briefing of the final themes was completed with the study's co-investigator and student researcher's doctoral advisor to add to the validity (Creswell, 2014).

Table 2

Codes Used Within the Final Themes

\begin{tabular}{|l|l|l|}
\hline Theme & Codes & Subthemes \\
\hline Impact & Emotions, Loss of Freedom, & 1) Facing A New Reality \\
Rituals, Routines, & 2) Lost Time and \\
Community Experiences, & Freedom \\
& Cancelled Plans, Miss, & 3) \\
& Friends, Family, Community & Social Participation \\
& IADLs & \\
\hline
\end{tabular}




\begin{tabular}{|c|c|c|c|}
\hline Adaptations & $\begin{array}{l}\text { Staying Connected, Virtual, } \\
\text { Benefits, Leisure, Social } \\
\text { Distancing, Productivity, } \\
\text { Coping, Adapting, Home } \\
\text { Management, Optimism, } \\
\text { Gratitude, Support, Physical } \\
\text { Activity, Helping Others }\end{array}$ & 2) & $\begin{array}{l}\text { Staying Connected } \\
\text { Remaining Engaged } \\
\text { in Purposeful } \\
\text { Occupations } \\
\text { Silver Lining }\end{array}$ \\
\hline Future Outlook & $\begin{array}{l}\text { Comfortable Return, Hesitant } \\
\text { Return, Future Outlook, } \\
\text { Thoughts on COVID-19, } \\
\text { Looking Forward, Health } \\
\text { Conditions }\end{array}$ & $\begin{array}{l}\text { 1) } \\
\text { 2) }\end{array}$ & $\begin{array}{l}\text { New Normal } \\
\text { Cautious Community } \\
\text { Return } \\
\text { Looking Forward to } \\
\text { Social Gatherings }\end{array}$ \\
\hline
\end{tabular}

Three major themes emerged from the experiences shared by older adults around the country: initial impact, adaptations, and future outlook.

Initial Impact. The sudden shock of COVID-19 brought about an exacerbation of emotions, new feelings, and changes in everyday life for the older adult population. Due to the complexity of the initial impact on seniors, this theme was further divided into three subthemes: facing a new reality, lost time and freedom, and loss of meaningful social participation.

Facing a New Reality. This subtheme portrayed the early emotions and experiences senior participants dealt with when facing a new reality.

I go to the store and I see people in masks and it's just so odd to see that, it's like a Twilight Zone, the streets are empty people are racing up and down the freeways - 
everyone's huddled in their houses - it's just so weird - and it's getting weirder - I don't see an end in sight (Participant 6).

Many participants spoke on unfamiliar feelings that came up while performing routine community IADLs such as grocery shopping.

Then the empty shelves have been extremely disorienting because we don't see that in this country - it's like oh my goodness if they got toilet paper we better grab some - you know even though you don't need, you feel like I better grab some (Participant 37).

Another participant discussed changes in social behavior when seeing a friend in public.

Even when you are in a store you don't feel like you can contact people because they are wearing their masks and everything - and they don't give you time as they are trying to behave themselves and you are trying to behave yourself (Participant 9).

Worrisome news headlines brought about feelings of fear and loss of interest in meaningful leisure.

At first when they told us 2 million people were going to die and so really watching the news all the time, and I found I couldn't concentrate on things, I enjoy knitting and sewing and I just couldn't really concentrate on those things... (Participant 35).

One elderly woman in her eighties shared how she noticed her usual positive outlook was difficult to maintain.

Watching the news and reading the paper I think you can't help but be a little - a lot of apprehension. It's a surprise for me to feel that way - usually I'm not a negative person and see the bad side of stuff I usually look at the positive, but this one is a tough one (Participant 40). 
New feelings of depression and exacerbation of existing depression were also evident. “...it's been really hard and I actually I have gone on an antidepressant” (Participant 16). "I take medication for depression... but one day I just cried...I would have to say what's hit me the most is just sad. The whole world's changing and it's hard to predict you know" (Participant 20).

Lost Time and Freedom. This subtheme captured the participants' views on how social distancing had affected their time and freedom within retirement. Although, older adults understand the importance of shelter in place during the pandemic, they expressed strong feelings of loss. One gentleman stated:

The only thing I'm upset about - well I wouldn't say upset but I'm 75 years old right so as you get older every day is more precious and you think about if I was younger maybe you lose like 6 months or so it's not a big deal, but as you get older you'd like to have those 6 months to do what I want to do - that's the purpose of retirement.... (Participant 32).

Another participant shared the sudden whirlwind of emotions that she endured at the onset of social distancing.

I realized this is scary - I got scared and I don't want to leave the house. Maybe I need to stay home, then I'm stuck, I can't do my normal activities, I'm losing privileges this is scary, how long is it going to go on, when will it end. I feel we are being robbed of our time (Participant 5).

Several others spoke on missing the spontaneity and ease of participating in community activities with friends. “... the spontaneity you just can’t go out to dinner, you just can’t go out to the movies, stuff like that" (Participant 41). Participant 34 remarked, "I miss getting together with friends and just the autonomy of just going to a restaurant and eating." Despite the social 
distancing mandate, participant 22 depicted her perspective as, "Yeah I don't feel cooped up at all and I don't feel isolated, I just feel like my wings have been clipped as far as spontaneous running around."

Loss of Meaningful Social Participation. This subtheme contained the various types of social participation older adults lost due to closure of community venues and social distancing mandates. They shared how usual meaningful social routines and rituals with friends were disrupted during this time. One woman in her seventies expresses,

I miss my routine... belong to exercise class, that's been cancelled, belong to women's groups - can't meet, miss my friends, and they are very friendly lovable warm and smart people and I miss the stimulating conversations with them (Participant 2).

Another woman who recently retired also lost participation in valuable leisure and faith related groups.

I don't have quilt guild meetings and I don't get to go to church on Sundays... I volunteered with adult day daycare center at our church... and I'm not doing that they're not even meeting. It's things like that, connecting with other people in the world (Participant 20).

A participant in her eighties could no longer attend the senior center for physical activity. "Well I go to the senior center for balance class and yoga twice a week, so I miss that" (Participant 23). One man would ritually meet with friends, “maybe $2-3$ times a week I'd go to the donut shop - talk to guys that are there... (Participant 36).

Plans to travel and spend quality time with family were forced to be cancelled without notice. 
This has been a very disappointing month; I should have been travelling to see my son who is having major surgery in Texas. Our airline has said that if we get there, they will isolate us for 2 weeks, so we cannot see him. And his daughter is graduating from high school - I wanted to be there to celebrate, I was at all my other grandchildren's graduations... (Participant 27).

Adaptations. The second overarching theme showed how despite the initial challenges, seniors demonstrated resilience through adaptation. Shelter in place became an opportunity to explore more leisure at home, stay connected to others, and see the bright side of a negative situation.

Staying Connected. In efforts to remain connected to family and friends, seniors utilized virtual platforms, phone calls, texts, emails, or meetings in person at a social distance. Many found comfort in reaching out to loved ones to check in. One woman who lived alone disclosed how improving communication with her family had helped her cope with depression.

I'm working harder at reaching out to my family... it's not the norm we communicate but it's like they don't want to intrude- but they're telling me they are worried about me. So, I think once we broke through that barrier...I'm doing better (Participant 16). Another participant in their early nineties, shared how the quality of conversations with family and friends have deepened.

I'm getting to know different aspects of my family that are not usual... I communicate with my friends back east and we talk some pretty serious stuff once in a while... (Participant 10).

More seniors have become more open to the idea of learning to use virtual platforms such as Zoom and FaceTime. "I had never done Zoom before and I've done that now several times" 
(Participant 20). Others have turned to these platforms to engage in social and faith related gatherings. "That's the one thing we do with video - we go mass online. And actually, we attend a number of different masses from different churches" (Participant 32). A woman in her late seventies had attended her local senior center's new virtual program. "They organize Zoom... each Friday 11 o'clock... we can talk, we can bring different what we know, song or story - it is like discussion club... it is very good." (Participant 19). Seniors also shared creative ways they were spending time with family over video calls. "My granddaughter, she just turned 7, calls me on Facetime and we'll chat - one day we played Chutes and Ladders for an hour and a half on Facetime” (Participant 20). Another stated, “Zoom parties with my brother and sister-in-law we've done... wine tasting” (Participant 39).

A few seniors were still meeting with a small number of friends, neighbors, and family at a safe social distance. "You know if my friend will call me and she wants to make dinner - we'll social distance on my patio you know far apart, and still wear a mask and everything" (Participant 23). One participant talked about staying connected with neighbors. "...visiting neighbors from a distance - doing driveway visits one of us at each end" (Participant 5). Another mentioned distanced family visits: "My son, when he delivers the groceries and his wife, they stay out front and we visit a little bit. I miss the closeness of giving a hug and that sort of thing" (Participant 40).

Remaining Engaged in Purposeful Occupations. With more time being spent at home seniors found ways to remain engaged in occupations that provided them with purpose. Older adults shared how they were staying active whether that be through leisure, physical exercise, and/or home management. One woman expressed the importance of creating an adapted routine to help ground her. 
I have been floating around a couple of days because my routine was off, so I figured out I had to establish a new routine - so you know getting into the habit of making coffee, getting the newspaper, checking the morning news, make the bed, make breakfast... (Participant 23).

Others were taking advantage of the time to be productive and tackle their to-do list. ...do more projects around the house than I normally would have, taking on more things that need to be done, cleaned up closets, got rid of a lot of old clothes. You know doing spring cleaning, which is probably more detailed than I normally would have done (Participant 18).

Some participants found purpose in using their skills to make things for others. A woman in her late 60s shared she was working with her church to make masks. "Our goal is to make a 1000 face masks before this is all said and done" (Participant 20). Another woman in her 70's stated she was knitting scarves for her close friends to pass the time.

I've been doing that for every one of my friends - and even if it's not their birthday yet I'm sending them one. You know it's not your birthday yet, but life is fragile so I'm sending it to you now (Participant 22).

Keeping a balance between leisure and physical activity was also discussed. "And since everything started, I've read more books than I can count, and I watch too much TV. But we actually, we do a lot of exercising by walking or bike riding every day" (Participant 32). Some people shared they were still having difficulty with finding purpose day to day. I had lots of reasons to go out in the past and of course that all falls away and I'm not a good routine discipline person although because I'm not into an established routine, I can 
get kind of confused about what day of the week is this, what am I supposed to get done today... (Participant 9).

Silver Lining. Older adults were able to find the good in a bad situation. A woman in her mid-seventies talked about what she learned to value during this time. "I think my friends and family all feel the value of family and friends, we are more aware of the value of connection and to be with family and friends, I value that more than ever" (Participant 30). Another participant in their late seventies spoke about how this time has caused her to be more appreciative. "I think it's made us step back to a simpler time - when you're not rushing about, you know and enjoying simpler things" (Participant 20). A younger senior in her mid 60s saw it as a preview to her transition into retirement "Gives me a way to kind of test retirement... it lets you slow down and smell the roses a little bit you know" (Participant 13).

Seniors expressed gratitude for small blessings in their lives "I have so much that is so good in my life that life - it is important to keep dwelling on that..." (Participant 4).

Environmental factors also made a positive impact on well-being "I just say that we are blessed to have wonderful weather, we can go outside - sit outside" (Participant 33).

Future Outlook. This final theme encompasses how seniors are coming to terms with the "new normal" and their comfort level of returning to the community once social distancing mandates are lifted.

Cautious Community Return. Although everyone was eager to get back to their regular community activities, when asked how comfortable they were with returning, the answers were mixed. The majority of people were hesitant to get back into crowded community spaces, even for social engagement they enjoyed. 
I will be cautious. I am not ready to go to big concerts with 100 s of people, not even ready to go back to church - I am attending services on line, mass on line. I am not ready to accept dinner invitations to a crowded restaurant (Participant 30).

The initial fears and lack of trust in the virus still linger without clear promise of safety I'm going to be very, very careful - I'm going to wear a mask - I'm going to treat it exactly like it is now - I'm not going to trust because this virus is going to be around for a long time (Participant 6).

Those at high risk due to pre-existing health conditions were more cautious I have asthma and it scares me willy nilly to think that I could die of this thing so I kind of see that I may not be as active out in the community as I was before - just for the fear it's going to be there... (Participant 20).

A handful of people were comfortable with traveling and going into public spaces while continuing to practice safety guidelines

I will go back - with a mask. I am not going to engage in events with large crowds, I'm going to go to less populated restaurants, and will go shopping but in off hours - late in the evening maybe. I will pick and choose my timelines (Participant 5).

This participant was very comfortable with returning "I don't have that big a problem going back as long as I know I can just keep my distance from everybody else, I don't have a problem about going back to restaurants" (Participant 36).

Desire for Social Contact. Almost everyone interviewed was looking forward to the social aspect of being out in the community without restriction. One man in his late seventies shared, "mostly being with family and friends and being relaxed together, not tense, not 8 feet apart and wearing a mask" (Participant 30). Multiple participants voiced looking forward to 
physical contact "Seeing family and being able to hug them" (Participants $24 \& 25$ ); and "What I miss most is being able to be physically with family. I miss physical contact and being able to hug my family and friends" (Participant 30). Physical gatherings were also missed "Looking forward to having dinner or lunch with people at our table” (Participant 37). All responses despite the variety of activities longed for boiled down to one desire "Being around people" (Participant 29).

Accepting a New Normal. When thinking about the future of our society, older adults understood that life would never be the same

I think people are going to come out of this feeling so different, it's just going to put a whole other thought process into the world and in the US about appreciation for what we had - because it's never going to go back to what we had (Participant 6).

One man in his late seventies spoke about coming to terms with change "I heard my wife say that things will permanently change and I kind of believe that too - we will have to make some changes with our lifestyle, this will make us make changes" (Participant 36).

Another woman expressed how important it is to be accepting

In a way it's kind of like a survival skill if you're not fighting something you're accepting it because that's the way it is - It's like being tolerant because you know this is the way it is right now, and you just have to work it out (Participant 22).

\section{Analysis of Part 2: Needs Assessment of Senior Organizations}

\section{Senior Organization Interviews}

Typed notes were taken from audio recordings and analyzed using similar qualitative methods to identify themes. The audio recordings were transcribed into a document and coded 
manually using the digital highlighting feature of Microsoft Word. Codes were grouped and refined to identify overarching themes.

Three overarching themes were identified from the five senior organization interviews conducted: impact on services, preventing social isolation, and adapting towards a new normal.

Impact on Services. Similarly to seniors, community organizations dealt with an abrupt change in pace. Valuable services such as meal and recreational programs were forced to be adapted. Every organization interviewed that offered meals to seniors reported it was one of their most popular services. Mealtime was a social opportunity to gather with friends. One organization representative described it as, "the heart and soul of our senior center... it really creates a sense of community" (Organization 4). Another center director observed that seniors would arrive a few hours early to pick up meals for the opportunity to socialize while wearing masks in line (Organization 3). Many organizations spoke about having to change from a congregate meal program to a pick or delivery model (Organization 2,3\&4). Organizations that had no foundation for a delivery model found it challenging to make the quick transition. One center director shared that they were pushed to make the change within 24 hours and were "one of the only cities that is having their own staff doing the deliveries" (Organization 4). Another center had support from their local police department to deliver meals to those who weren't able to do curbside pickup (Organization 2).

Popular in person recreational programs such as exercise, wellness, and leisure classes could no longer be offered. Many organizations felt the push for creating virtual programming to fill the void, although that came along with its own challenges including: interest, accessibility, learning new platforms, and cost. Senior centers were concerned about how familiar older adults were with social media and video conferencing platforms like Zoom and Facebook. One center 
has utilized Facebook Live to offer fitness classes, live singers, and trivia games (Organization 3). However, the same center was still facing obstacles with teaching seniors how to use virtual platforms and reaching those who did not have internet access. Another center was still deciding if their investment in creating virtual programming would be received well by the seniors within their community (Organization 4). Anecdotal feedback was shared about how a senior they knew tried virtual programming elsewhere and felt stressed by the virtual environment. Despite that instance, they went on to say, "even if we could reach 20 seniors it would be worth it" (Organization 4).

Organizations that provided resources to low income seniors to find housing, home repair, and other supportive services continued to provide aid over the phone. An increase of three new clients was seen by one organization in need of assistance for food, mental health concerns, and home repairs was seen (Organization 1). In home services provided by another resource organization were also impacted (Organization 5). They reported having to limit contact with clients to an as-needed basis with use of proper protective equipment. Supplies were delivered and family members were contacted to help clients install new items within the home.

Preventing Social Isolation. All of the organizations interviewed expressed concern about the rising risk for social isolation during this time. Every organization had some form of a phone call program to check in on seniors within their communities. "Keeping seniors from feeling isolated is one of our core values" stated one center (Organization 4). Phone calls to regular attendees and past participants were made to offer help if needed. One of the senior resource organizations stated that when they reached out to past clients, the majority of people were doing well but several needed services again (Organization 1). Another senior resource organization reported that during their check in calls they were providing creative suggestions for 
seniors to keep in touch with others (Organization 5). The same organization shared they had to begin assisting older adults with technology over the phone due to seniors reaching out for help. This highlighted the value of technology skills to remain connected.

Adapting Towards a New Normal. All the organizations interviewed expressed that they were concerned for the safety of their seniors and were hard at work to adapt towards a new normal. Questions regarding how to help seniors recover, when it would be safe, and what protocols to use were voiced by Organization 5. Three organizations shared that they were planning to survey their respective communities continually to better understand their needs and comfort level with returning (Organization 2,3\&4). Mixed feelings on resuming social activities within the community were anticipated.

Creating safe environments upon return was also a priority. Elements of creating a screening process included the addition of temperature check kiosks, plexiglass barriers, and through cleaning of high touch points (Organization 2,3\&4). Centers understood they would be required to reopen at reduced capacity to follow specific county guidelines. One center stated they would enforce this by reducing class sizes and "having people return by alphabetical last name" (Organization 3). The same center reported it would be a big change since they normally saw “350-400 people a day.” Another center was considering cutting drop in activities and having participants pre-register to reduce crowds (Organization 2).

Organizations also realized that there would be seniors who never felt safe returning and therefore virtual programming would remain necessary. The need for increasing accessibility and usability of technology was also identified as future programming opportunities. 


\section{Chapter 5: Discussion and Conclusion}

\section{Discussion}

This qualitative capstone project evolved to focus on the impact of the current primary barrier to social participation and shared first-hand experiences of independently living older adults $(n=42)$ and community senior organizations $(n=5)$ during social distancing. The COVID19 pandemic brought about new unforeseen challenges for both groups, however both groups demonstrated resilience.

The impact on seniors followed three clear themes that showed the complexity of initial impact on older adult's lives, their ability to adapt, and their future outlook. Sudden onset of a novel virus and social distancing precautions led to a new reality that many had never experienced. The seniors' unexpected loss of meaningful social participation with friends, family, and community social groups was a deprivation of human connection. Many seniors were dealing with new or exacerbated emotions of fear and sadness while others felt loss of freedom. New restrictions within the community brought about a change in social atmosphere that seniors noticed during routine activities such as grocery shopping.

Despite the new challenges faced, older adults found ways to remain connected to loved ones. The majority of participants made efforts to reach out and check in on friends and family through phone and video calls. New platforms such as Zoom were learned to continue rituals with social groups. With more time at home, participants created new routines to stay engaged in purposeful occupations through leisure and home management. Older adults remained positive during this uncertain time by focusing on the silver lining and expressing gratitude for their blessings. 
As social distancing continued, a growing desire for meaningful social contact and participation in social activities without tension became evident. However, emotions of apprehension, fear, and uncertainty still lingered. When discussing the final theme, their future outlook, participants remembered initial impacts. For example, when asked about their level of comfort with returning to the community post-social distancing, the majority of participants felt hesitant. The few that were ready were still planning to maintain safety precautions, such as wearing a mask and social distancing in crowded areas. Ultimately seniors were coming to terms with accepting a new reality and understanding that they would have to make lifestyle changes that contribute to their wellbeing. The interview participants were navigating the uncertainty day by day.

Senior organizations went down a similar path of dealing with the initial effects of closures on their services, making modifications, and adapting services for a new normal. Organizations were concerned for the wellbeing of seniors within their respective communities. Although all organizations were forced to cease in person services for the safety of their participants, they continued to check in by phone to prevent social isolation. New challenges discussed were creating safe environments upon return, understanding senior needs, making virtual programming accessible, and aiding in the recovery of older adults post-pandemic were discussed. The majority of organizations were creating new solutions and programming that can help to support seniors during and after social distancing.

The long-lasting effects of social distancing on mental, physical and social health are unknown at this time, but these senior participants suggested it would have a lasting toll on their emotional wellbeing and desire for social connection. These findings can inform senior 
organizations (senior centers, independent living facilities, and other resource centers) of the experiences of seniors during social distancing and their future needs.

\section{Recommendations and Implications for Occupational Therapy}

The findings from this study can help inform OT practitioners on how to help senior organizations and struggling seniors adapt towards a new normal within the community. Three key takeaways became evident from this study: 1) remaining engaged in purposeful occupations and staying connected aided ability to adapt; 2) transitioning towards a new normal came in stages; and 3) the need to get seniors more comfortable with technology became essential. The AOTA supports the role of occupational therapy in senior centers to help older adults cope with life transitions, create routines or lifestyle changes that support well-being, and educate on new skills (Toto, 2016). OT practitioners could utilize the findings from this study to support wellbeing of seniors after the pandemic.

The transition towards a new normal may be difficult for certain groups of seniors. Making lifestyle changes and coping with the long-term effects of the pandemic may require additional support. OTs can help seniors through various stages of acceptance and recommend occupational adaptations as necessary. This could be done by helping seniors create new routines that would support autonomy despite the pandemic-related barriers. Routines and engagement in purpose driven occupations can enhance quality of life. AOTA recognizes productive aging as a key practice area for OT (AOTA, n.d.). Productive aging for community dwelling seniors can be promoted through engagement in meaningful occupations (Leland \& Elliott, 2012). The MOHO can be used to support seniors who are struggling with motivation and change (Cole \& Tufano, 2008). 
Social distancing has highlighted the value of having skills in technology. There is a need expressed by senior organizations and the literature to bridge the gap in technological literacy. Occupational therapists can work with senior centers to teach basic skills in utilizing virtual platforms such as Zoom to promote the use of virtual programming. Classes can be adapted to meet the various skill levels of seniors. The PEOP model can be used to modify virtual environments to enhance engagement and create more opportunities for social connection over distance.

Feelings of unease with returning to community social activities is largely dependent on the fear of catching the virus. In this case, focus must be put on factors that are within our control such as the environment. The PEOP model can help guide occupational therapy intervention and recommendation on creating supportive virtual and physical environments to enhance occupational engagement. Activity analysis can also be used to better understand how occupational performance within the community may be impacted by safety mandates (i.e. wearing masks and social distancing). In addition to ensuring safe physical environments that follow protocol for reducing the spread of the virus, creating a welcoming space that reduces anxiety is beneficial.

\section{Limitations and Future Considerations}

Given the unpredictability of the virus and the unknown duration of social distancing mandates there were several limitations to this study. Despite efforts to reach a number of senior organizations around the country, only a handful agreed to be interviewed. This may be a result of increased closures and decreased willingness to share during this stressful time. Another limitation is that the experiences shared cannot be generalized to a larger population due to decreased diversity within the participant pool. Convenience sampling was utilized due to the 
short timeframe of the study. Majority of the participants did not utilize senior centers and older adults with lower socio-economic status were underrepresented.

After completion of this study, many future considerations for research emerged. One possibility involves completing a more focused study to look at the impact of social distancing on seniors who utilized one specific senior center. This would provide targeted feedback to inform a specific organization on how they can meet the current and future social participation needs. Understanding the impact on populations of seniors who are more in need of community support such as low-income, older adults who live alone, and those with chronic health conditions could be more intriguing. Thirdly, a follow up study looking into the effectiveness of OT intervention on recovery of seniors post-COVID-19.

\section{Dissemination}

Findings from this study were presented to senior organizations virtually via PowerPoint (see appendix E) to inform them of senior experiences at the end of August 2020. Recommendations for supporting community reintegration were also shared as a PDF handout (see appendix F). This capstone project will be submitted for consideration of journal publication to add to the new body of COVID-19 related literature (see appendix G) for reasoning for journal publication.

\section{Conclusion}

This research study adds to a new body of Covid-19 related literature. The experiences shared within this study are specific to the initial onset of social distancing mandates. As social distancing mandates continue past the completion of the study (August 2020) the experiences and views of seniors and organizations are subject to change. The long-lasting effects of social distancing on seniors are unknown at this time. This study serves as a stepping stone for further 
exploration into occupational therapy's role in recovery of seniors and support throughout the community reintegration process. 


\section{References}

All About Seniors. (2017). Senior centers defined. https://www.allaboutseniors.org/seniorcenters-defined

American Occupational Therapy Association. (n.d.). Productive aging. https://www.aota.org/Practice/Productive-Aging.aspx

American Occupational Therapy Association. (2014). Occupational Therapy Practice Framework: Domain and Process (3rd ed.). American Journal of Occupational Therapy, 68 (Suppl.), S1-S48. https://doi.org/10.5014/ajot.2014.682006

American Occupational Therapy Association. (2016). Occupational therapy's role in senior centers. https://www.aota.org/About-Occupational-

\section{Therapy/Professionals/PA/Facts/senior-centers.aspx}

Ashida, S., \& Heaney, C. A. (2008). Social networks and participation in social activities at a new senior center: Reaching out to older adults who could benefit the most. Activities, Adaptation \& Aging, 32(1), 40-58.

Aung, M. N., Yuasa, M., Koyanagi, Y., Aung, T. N. N., Moolphate, S., Matsumoto, H., \& Yoshioka, T. (2020). Sustainable health promotion for the seniors during COVID-19 outbreak: a lesson from Tokyo. Journal of Infection in Developing Countries, 14(4), 328331. https://doi.org/10.3855/jidc.12684

Braun, V., \& Clarke, V. (2006). Using thematic analysis in psychology. Qualitative Research in Psychology, 3(2), 77-101.

Campbell J, \& Aday RH. (2001). Healthy People 2010. Benefits of a nurse-managed wellness program: a senior center model: Using community-based sites for older adult intervention and self-care activities may promote an ability to maintain an independent lifestyle. 
Journal of Gerontological Nursing, 27(3), 34-43.

http://search.ebscohost.com/login.aspx?direct=true\&db=ccm\&AN=107021699\&site=eds -live

Cattan, M., Hogg, E., \& Hardill, I. (2011). Improving quality of life in ageing populations: What can volunteering do? Maturitas, 70(4), 328-332. https://doi.org/10.1016/j.maturitas.2011.08.010

Centers for Disease Control and Prevention. (2018). Well-being concepts. https://www.cdc.gov/hrqol/wellbeing.htm\#three

Centers for Disease Control and Prevention. (2020a). Loneliness and social isolation linked to serious health conditions. https://www.cdc.gov/aging/publications/features/lonely-olderadults.html\#: : :text=Older $\% 20$ adults $\% 20$ are $\% 20$ at $\% 20$ increased, the $\% 20$ amount $\% 20$ of $\%$ 20social $\% 20$ contact.

Centers for Disease Control and Prevention. (2020b). Older adults. https://www.cdc.gov/coronavirus/2019-ncov/need-extra-precautions/older-adults.html Centers for Disease Control and Prevention. (2020c). Social distancing. https://www.cdc.gov/coronavirus/2019-ncov/prevent-getting-sick/social-distancing.html

Chen, L. K. (2020). Older adults and COVID-19 pandemic: Resilience matters. Archives of Gerontology and Geriatrics, 89, 104124. https://doi.org/10.1016/j.archger.2020.104124

Christiansen, C., \& Baum, C. M. (2005). Occupational therapy: Enabling function and wellbeing ( $3^{\text {rd }}$ ed.). SLACK Incorporated.

Christiansen, C. H., Baum, C. M., \& Bass-Haugen, J. (2005). Person-environment-occupationperformance: An occupation-based framework for practice. In C. H. Christensen, C.M. 
Baum, \& J. Bass-Haugen (Eds.), Occupational therapy: Performance, participation, and well-being (3rd ed.). SLACK Incorporated.

Clark, F., Azen, S. P., Zemke, R., Jackson, J., Carlson, M., Mandel, D., Hay, J., Josephson, K., Cherry, B., Hessel, C., Palmer, J., Lipson, L. (1997). Occupational therapy for independent-living older adults: A randomized controlled trial. JAMA, 278(16), 13211326.

Clark, F., Jackson, J., Carlson, M., Chou, C., Cherry, B. J., Jordan-Marsh, M., Knight, B. G., Mandel, D., Blanchard, J., Granger, D. A., Wilcox, R. R., Lai, M. Y., White, B., Hay, J., Lam, C., Marterella, A., Azen, S. P. (2012). Effectiveness of a lifestyle intervention in promoting the well-being of independently living older people: Results of the well elderly 2 randomised controlled trial. Journal of Epidemiology and Community Health, 66(9), 782. https://doi.org/10.1136/jech.2009.099754

Cole, M. B., \& Tufano, R. (Eds.). (2008). Applied theories in occupational therapy: A practical approach. Slack Incorporated.

Creswell, J. W. (2014). Research design: Qualitative, quantitative, and mixed methods approaches (Fourth edition). SAGE Publications, Inc.

Dattilo, J., Lorek, A. e., Mogle, J., Sliwinski, M., Freed, S., Frysinger, M., \& Schuckers, S. (2015). Perceptions of leisure by older adults who attend senior centers. Leisure Sciences, 37(4), 373-390. http://prxusa.lirn.net/login?url=http://search.ebscohost.com/login.aspx?direct=true $\& \mathrm{db}=\mathrm{s} 3 \mathrm{~h} \& \mathrm{AN}=$ $\underline{103167639 \& \text { site }=\text { eds-live }}$

Ejiri, M., Kawai, H., Fujiwara, Y., Ihara, K., Watanabe, Y., Hirano, H., Kim, H. K., Ishii, K., Oka, K., \& Obuchi, S. (2019). Social participation reduces isolation among Japanese older 
people in urban area: A 3-year longitudinal study. PLoS ONE, 9. https://doi.org/10.1371/journal.pone.0222887

Fitzpatrick, T. R., McCabe, J., Gitelson, R., \& Andereck, K. (2006). Factors that influence perceived social and health benefits of attendance at senior centers. Activities, Adaptation \& Aging, 30(1), 23-45. https://doi.org/10.1300/J016v30n01_02

Gibbs, G. R. (2007). Analyzing qualitative data. In U. Flick (Ed.), The Sage qualitative research kit. Thousand Oaks, CA: Sage

Hitchcott, P. K., Fastame, M. C., \& Penna, M. P. (2018). More to Blue Zones than long life: Positive psychological characteristics. Health, Risk \& Society, 20(3-4), 163-181.

John Hopkins Medicine. (2020). What is Coronavirus?

\section{https://www.hopkinsmedicine.org/health/conditions-and-diseases/coronavirus}

Kadowaki, L., \& Mahmood, A. (2018). Senior centres in Canada and the United States: A scoping review. Canadian Journal on Aging/La Revue canadienne du vieillissement, 37(4), 420-441.

Kielhofner, G. (2002). A model of human occupation : Theory and application (3rd ed.). Williams \& Wilkins

Krout, J. A. (1982). Correlates of senior center utilization. Research on Aging, 5(3), 339-352.

Leland, N. E., \& Elliott, S. J. (2012). Special issue on productive aging: Evidence and opportunities for occupational therapy practitioners. The American journal of occupational therapy: Official publication of the American Occupational Therapy Association, 66(3), 263-265. https://doi.org/10.5014/ajot.2010.005165

Li, F., Harmer, P., \& Fitzgerald, K. (2016). Implementing an Evidence-Based Fall Prevention Intervention in Community Senior Centers. American Journal of Public Health, 106(11), 
2026-2031.

http://search.ebscohost.com/login.aspx ?direct $=$ true $\& d b=$ cmedm $\& A N=27631751 \&$ site $=\mathrm{e}$ $\underline{\text { ds-live }}$

National Academies of Sciences, Engineering, and Medicine. (2020). Social Isolation and Loneliness in Older Adults: Opportunities for the Health Care System. Chapter 1: Introduction. National Academies Press (U.S.)

National Institute of Health. (2019). Social isolation, loneliness in older people pose health risks. https://www.nia.nih.gov/news/social-isolation-loneliness-older-people-pose-health-risks

Nedelcu, E. (2018). The Impact of Social Relationships over Health and Longevity. The "Blue Zones" Case. Challenges of the Knowledge Society, 12, 1077-1083.

Noel, P. H., Parchman, M. L., Finley, E. P., Wang, C. P., Bollinger, M., Espinoza, S. E., \& Hazuda, H. P. (2016). Primary care-public health linkages: Older primary care patients with prediabetes \& type 2 diabetes encouraged to attend community-based senior centers. Preventive Medicine Reports, 4, 283-288.

Office of Disease Prevention and Health Promotion. (2014). Healthy People 2020: Older adults. https://www.healthypeople.gov/2020/topics-objectives/topic/older-adults

Plagg, B., Engl, A., Piccoliori, G., \& Eisendle, K. (2020). Prolonged social isolation of the elderly during COVID-19: Between benefit and damage. Archives of Gerontology and Geriatrics, 89, 104086. https://doi.org/10.1016/j.archger.2020.104086

Rosenbaum, M. S., Sweeney, J. C., \& Massiah, C. (2014). The restorative potential of senior centers. Managing Service Quality, 24(4), 363-383.

Smallfield, S., \& Molitor, W. L. (2018). Occupational therapy interventions supporting social participation and leisure engagement for community-dwelling older adults: A systematic 
review. AJOT: American Journal of Occupational Therapy, 4, 1.

https://doi.org/10.5014/ajot.2018.030627

Stav, W. B., Hallenen, T., Lane, J., \& Arbesman, M. (2012). Systematic review of occupational engagement and health outcomes among community-dwelling older adults. American Journal of Occupational Therapy, 66(3), 301-310.

Tomioka, K., Kurumatani, N., \& Hosoi, H. (2017). Age and gender differences in the association between social participation and instrumental activities of daily living among community-dwelling elderly. BMC Geriatrics, 17(1), 99.

Toto, E. P., (2016). AOTA Fact sheet: Occupational therapy's role in senior centers. https://www.aota.org/ /media/Corporate/Files/AboutOT/Professionals/WhatIsOT/PA/Fac ts/Senior $\% 20$ Centers $\% 20$ fact $\% 20$ sheet.pdf

Tull, M. T., Edmonds, K. A., Scamaldo, K. M., Richmond, J. R., Rose, J. P., \& Gratz, K. L. (2020). Psychological outcomes associated with stay-at-home orders and the perceived impact of COVID-19 on daily life. Psychiatry Research, 289, 113098. https://doi.org/10.1016/j.psychres.2020.113098

Turcotte, P.-L., Carrier, A., Roy, V., \& Levasseur, M. (2018). Occupational therapists' contributions to fostering older adults' social participation: A scoping review. British Journal of Occupational Therapy, 81(8), 427-449. https://doi.org/10.1177/0308022617752067

Van Orden, K. A., Bower, E., Lutz, J., Silva, C., Gallegos, A. M., Podgorski, C. A., Santos, E. J., \& Conwell, Y. (2020). Strategies to Promote Social Connections Among Older Adults During "Social Distancing” Restrictions. The American Journal of Geriatric Psychiatry. https://doi.org/10.1016/j.jagp.2020.05.004 
Vieira, E. R., Richard, L., \& da Silva, R. A. (2020). Perspectives on research and health practice in physical and occupational therapy in geriatrics during and post COVID-19. Physical \& Occupational Therapy in Geriatrics, 38(3), 199-202.

https://doi.org/10.1080/02703181.2020.1786906

Wanchai, A., \& Phrompayak, D. (2019). A systematic review of factors influencing social participation of older adults. Pacific Rim International Journal of Nursing Research, 23(2), 131-141.

$\underline{\text { http://search.ebscohost.com/login.aspx?direct=true } \& \mathrm{db}=\mathrm{ccm} \& \mathrm{AN}=135543087 \& \text { site=eds }}$ $\underline{- \text { live }}$

Wikipedia. (2020). Timeline of the COVID-19 pandemic in May 2020. https://en.wikipedia.org/wiki/Timeline of the COVID-19 pandemic_in_May_2020 
Appendix A

IRB Approval Letter

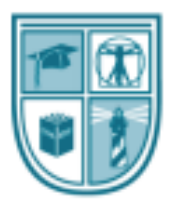

\section{UNIVERSITY OF ST. AUGUSTINE \\ F O R R H E A L T H S C I E N C E S}

To:

Dr. Chris Childers, Principal Investigator

From:

Iman Akef Khowailed, DSc.

Re: IRB \# 0424-020

Title: Exploring the impact and effects of mandated social distancing on the older adult

The Institutional Review Board (IRB), responsible for the review of research involving human subjects, has reviewed and approved the amendments to your proposal that you requested on April 30th, 2020.

These amendments include adding Salina Jivan, OTDS as student investigator and adding three new interview questions.

- This approval expires on April $25^{\mathrm{th}}, 2021$.

Please contact me if you have any questions.

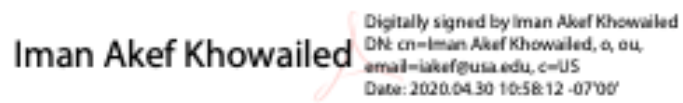

Sincerely,

Iman Akef Khowailed PT, MPT, MPH, DSc

California IRB Chair 


\section{Appendix B}

\section{Senior Interview Questions}

Thank you for agreeing to participate in this interview. My name is Chris/Salina and I am trying to understand the impact of social distancing on adults over the age of 65 . This interview is being recorded so I can write it out later, but any personal details will be kept private and confidential.

First, I am going to ask you a few questions about yourself:

First name:

Age:

Current living location:

Senior community (over 55 community, senior housing complex)

Community location not specifically for seniors

Lives alone

Lives with others - Indicate: spouse, caregiver, family member(s)

Other: specify

\section{Interview Questions}

- What do you miss the most as a result of social distancing? Give examples

- What are you looking forward to doing once social distancing is lifted? Give examples

- Do you have the technology to talk to people and see them while you are talking? 
- Do you own a smart phone?

- How are you remaining social/connected during this time?

- Are you participating in physical activity - if so what and how often?

- What are the benefits if any of social distancing? Give examples

- Can you give me one word that you feel describes your usual personality? (try not to give examples but if required suggest "happy," "outgoing," "quiet")

- Have you noticed any changes in your mood or affect since social distancing started?

- On a scale of $1-10$, where 1 is not at all and ten is all the time, how lonely are you these days?

- Have you noticed any changes in your health since social distancing started?

- How have your daily routines changed during social distancing?

- How do you feel about going back into the community once social distancing mandates are lifted? What do you plan on doing?

- Is there anything else you would like to tell me about how you have felt since the start of social distancing? 


\section{Appendix C}

6 Item Cognitive Impairment Test

\begin{tabular}{|c|c|c|c|}
\hline & & & $\begin{array}{l}\text { Client } \\
\text { score }\end{array}$ \\
\hline 1 & What year is it? & $\begin{array}{l}\text { Correct } 0 \text { points } \\
\text { Incorrect } 4 \text { points }\end{array}$ & \\
\hline 2 & What month is it? & $\begin{array}{l}\text { Correct } 0 \text { points } \\
\text { Incorrect } 3 \text { points }\end{array}$ & \\
\hline 3 & $\begin{array}{l}\text { Give the patient the following address: } \\
\text { John, Smith, 41, Main Street, Washington }\end{array}$ & & \\
\hline 4 & About what time is it? - within 1 hour & $\begin{array}{l}\text { Correct } 0 \text { points } \\
\text { Incorrect } 3 \text { points }\end{array}$ & \\
\hline 5 & Count backwards from 20 & $\begin{array}{l}\text { Correct } 0 \text { points } \\
1 \text { error } 2 \text { points } \\
\text { More than } 1 \text { error } 4 \text { points }\end{array}$ & \\
\hline 6 & Say the months of the year in reverse & $\begin{array}{l}\text { Correct } 0 \text { points } \\
1 \text { error } 2 \text { points } \\
\text { More than } 1 \text { error } 4 \text { points }\end{array}$ & \\
\hline 7 & $\begin{array}{l}\text { Repeat the address - note the } 5 \text { areas: } \\
\text { John } \\
\text { Smith }\end{array}$ & $\begin{array}{l}\text { Correct } 0 \text { pints } \\
1 \text { error } 2 \text { points } \\
2 \text { errors } 4 \text { points }\end{array}$ & \\
\hline
\end{tabular}




\begin{tabular}{|l|l|l|l|}
\hline 41 & 3 errors 6 points & \\
& Main street & 4 errors 8 points & \\
& Washington & All wrong 10 points & \\
\hline & & Total score & \\
\hline
\end{tabular}

Cut off score $0-7=$ normal

8 or higher - more significant

If individual scores 7 or below, the continue with the interview 


\section{Appendix D}

\section{Senior Organization Interview Questions}

- Prior to the pandemic, what were the most utilized services that your organization offered?

- During the pandemic, what challenges has your organization faced?

- How have you adapted your services?

- How successful have those adaptations been?

- What challenges or needs do you foresee for the senior population once social distancing mandates are lifted?

- How does your organization plan on making seniors feel safe when reintegrating back into community recreation? 


\section{Appendix E}

\section{Power Point Presentation for Senior Organizations}
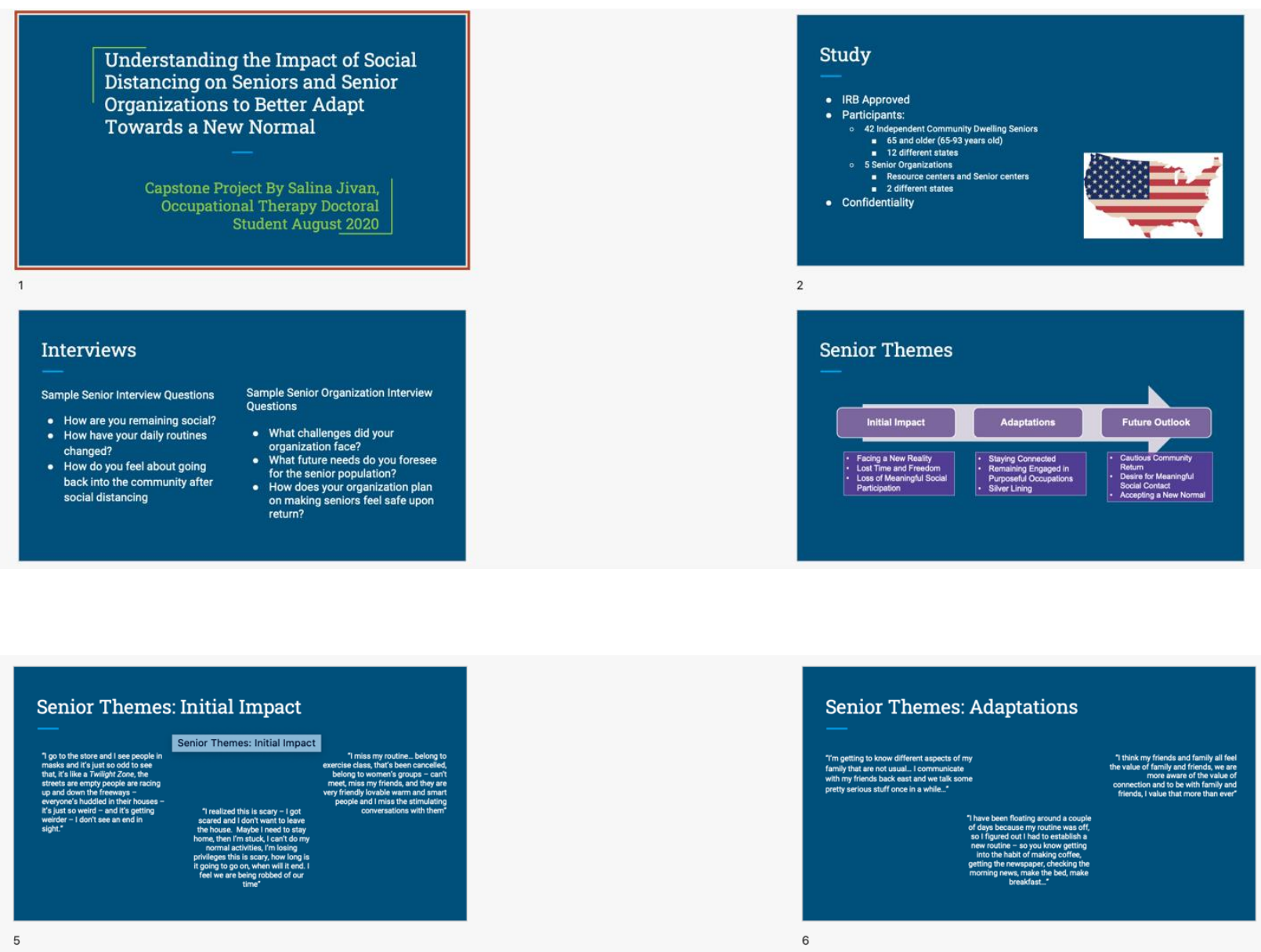

Senior Themes: Future Outlook

Senior Organization Themes
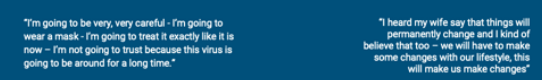


\section{Appendix F}

\section{Recommendations Handout}
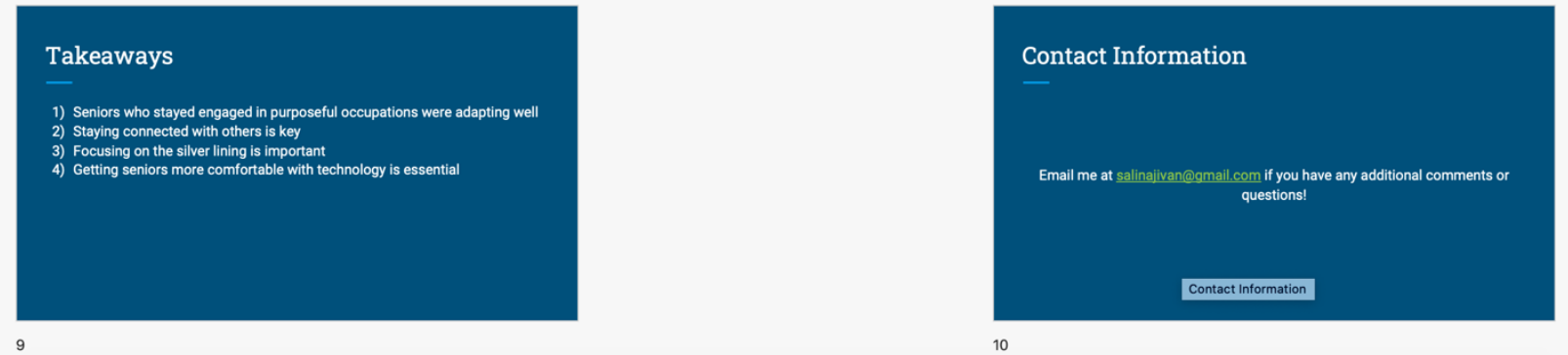
Supporting the Recovery of Seniors

By Salina Jivan, Occupational Therapy Doctoral Student (August 2020)

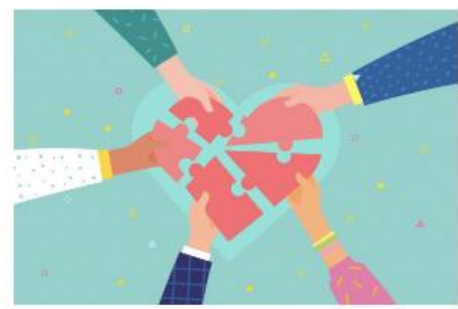

The long-term physical, social, and psychological effects of social distancing on older adults is not well understood at this time. Seniors within this study showed a lasting emotional toll from the initial onset of COVID-19 that has made them cautious about return to community activities. Those who were adapting well stayed busy through purposeful routines and occupations (leisure, home management, and exercise). Continued engagement in meaningful occupations can contribute to productive aging within the community (Leland \& Elliot, 2012).

Bringing Seniors Together with Purpose

Create opportunities for seniors to come together and give back to the community.

Collaboration can be done from home and in person when safe enough to gather. Keep communication amongst the group open through emails, phone calls and video call. Allow the group to come up with achievable goals to keep them motivated.

- Goal Driven Ideas:

- Sew masks for a community in need or local nursing home

- Donate items from spring cleaning to local church or charity

- Raise money for those in need

- Utilize the strengths/skills of the group to come up with creative ideas

- Seniors helping seniors

- Buddy program to check in on each other via phone calls

- Intergenerational connections

- Pen pal system with a local school

- Virtual collaboration with college students

- Opportunity to share wisdom and life experiences 
Encourage Healthy Routines

With more time being spent at home many seniors have experienced a shift in routines. Seniors who were adapting well expressed how they created new routines to maintain their wellbeing during quarantine. With this in mind, a program can be created to help seniors adapt and make new routines that support their mental, physical and social health.

- Have seniors write out their current routines to identify activities that have been lost due to social distancing

- Help seniors find ways they can adapt for those losses

- Ex: Someone who can no longer attend their normal gym classes might consider going on walks in their neighborhood with another friend

- Ask seniors to think about the activities in their daily routines that contribute to their mental, physical, and social health. This will put focus on incorporating activities that contribute to overall health.

- Offer suggestions as needed and allow seniors to share new ideas amongst each other

- Mental

- Playing with a pet

- Sitting outside with a cup of coffee

- Meditation or prayer

- Physical

- Going for walks

- Cleaning the house

- Playing tennis

- Social

- Calling friends

- Spending time with spouse

- Video calling family

- Additionally, these tools can be used to help seniors identify areas in their life that could use more attention.

- Wheel of life

- https://wheeloflife.noomii.com/

- This interactive online looks at 8 areas within a person's life (health, spirituality, family, etc.) and allows the individual to rate how satisfied they are with each category

- Offers a visual of what areas someone may want to improve

- Printable version

- https://s3-ap-southeast-2.amazonaws.com/universallifetoolsmsh/PDFs/wheel-life-balance.pdf

- Color in each section by hand

- Have seniors share their results and one step they will take to improve their weakest area. 
Rebuilding a sense of community

Seniors within the study voiced their caution with returning community recreation due to fear of the virus. Once social distancing mandates are lifted there may be residual apprehension to be back at the senior center.

- Supportive environments

- Reduce anxiety by creating a welcoming environment

- Add music

- Use color

- Keep areas of the environment that don't conflict with safety protocols familiar

- Slowly get seniors comfortable with small gatherings once safe to do so in your county - Outdoor picnic

- Catching up friends and staff they haven't seen in a long time

- Allows seniors to be in an open space and reduce anxieties around being in large groups

- Outdoor movie night

- Requires a projector and screen for viewing

- Seniors can bring family, blankets, and snacks to enjoy the movie outdoors

Reference

Leland, N. E., \& Elliott, S. J. (2012). Special issue on productive aging: Evidence and opportunities for occupational therapy practitioners. The American journal of occupational therapy: Official publication of the American Occupational Therapy Association, 66(3), 263-265. https://doi.org/10.5014/ajot.2010.005165 
Getting Seniors More Comfortable with Technology

By Salina Jivan, Occupational Therapy Doctoral Student (August 2020)
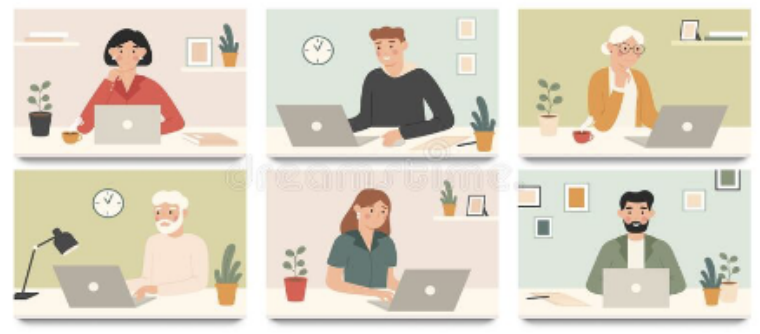

Social distancing during the COVID-19 pandemic has highlighted the importance having skills in technology to remain connected with friends and family. Some seniors have embraced technology and others may need more assistance. Offering classes and services that help bridge the technology gap amongst seniors has become essential.

It is important to consider the various competence levels and personal goals of technology use when developing programming.

- Survey seniors:

- To understand what types of devices (iPhone, Android, government cell phones, tablet, laptop, etc.) they are using

- What their goals with technology are?

- Sending texts, photos, and email

- Social Media

- Video calling

- Virtual programming

- How comfortable they are with using technology?

Meeting the needs of various competence levels

- Smaller class sizes with groups of seniors who have similar skill levels and goals

- Allowing opportunity for peers who feel more comfortable with technology to teach other seniors by leading a session.

- Seniors can create a cheat sheet, video, or presentation to help their peers learn

- Be aware of various learning styles (visual, audio, and kinesthetic)

- Handouts with step by step instructions including pictures can be helpful for recall 
- Pre-recorded videos walking through steps is great for audio visual learners and allows seniors to go at their own pace

Increasing exposure to various uses of technology

- Weekly classes where seniors can learn something new and share their knowledge with peers

- A few ideas:

- sharing favorite smartphone apps and podcasts

- how to post on social media

- how to use delivery service apps

- how to share photos with family and friends

- how to throw a virtual party with friends and family over Zoom

Engaging Virtual Programming to Enhance Social Participation Over Distance Social contact with others has become more desirable as social distancing mandates continue. Virtual programming can offer opportunity to connect with peers and engage in meaningful discussions. Once social distancing mandates have been lifted, virtual programming can serve older adults who don't feel comfortable returning to the community right away. Below are some tips how to keep seniors engaged during virtual programming.

\section{Avoid}

- Pre-recorded videos

- Lecture style programming

\section{Consider}

- Recording live classes real time for participants at home to join

- Creating more opportunity for discussion

- Using a consistent platform that seniors can easily learn such as Zoom

Hosting Tips

- Facilitate more conversation by:

- Asking seniors to share personal experiences and opinions

- Having participants use raise hand feature

- https://nerdschalk.com/how-to-raise-hand-on-zoom/

- Participants can be broken up into smaller groups within Zoom to encourage discussion amongst peers

- https://support.zoom.us/hc/en-us/articles/206476313-Managing-breakoutrooms

- Encourage use of the chat box for commentary

- Hold a practice session $30 \mathrm{~min}$ before the actual programming to get seniors comfortable with logging on and using features within the virtual platform (chat box, raise hand feature, adjusting their camera, etc.)

- This will also provide ample time to ask questions 
Virtual Programming Ideas

- Weekly virtual lunch hour with discussion

- Seniors can have lunch virtually and discuss the chosen topic for the day

- Topics can include:

- Favorite childhood memory

- Share how you're staying in touch with friends

- Help seniors gain new and creative ideas

- Share your quarantine routine

- Can help seniors who are struggling with finding a routine learn from peers

- Share a little about your favorite hobby

- Potential for teaching it to everyone in future classes

- How do you enjoy staying active?

- Best thing you've ever eaten?

- Share your favorite song?

- Host can find song on YouTube and play it for everyone

- Opportunity for nostalgia and stimulation of more conversation

- Activities

$\circ$ Movie night

- Hold a poll to see which movie everyone wants to watch

- Host plays movie and shares their screen

- Make time for discussion after

- What was your favorite part of the movie?

- How did you feel about the ending?

- How would you rewrite the ending?

- Who was your favorite character and why?

- Trivia night

- Choose a theme for trivia that's relatable

- Guess that song?

- Play a clip from popular music from different decades

- Quizlet can be used for creating own trivia questions or searching pre-made collections

- Break people into teams

- Utilize the rooms and raise hand feature

- Add incentive with prizes

- Talent show

- Have seniors share their talents

- Anonymous voting can be done using poll feature on Zoom

- https://support.zoom.us/hc/en-us/articles/213756303-Polling-formeetings

- Give audience a chance to comment on participant's performances

- Encourage use of the chat box 


\section{Appendix G}

\section{Journal Publication}

This research study, "Understanding the Impact of Social Distancing on Older Adults and Senior Organizations to Better Adapt Towards a New Normal" will be tentatively submitted to the Annals of International Occupational Therapy for publication. This journal is currently looking for research that looks into the role of occupational therapy in the new normal of COVID-19. This research study fits the criteria of the topics the journal is seeking because it informs how OT practitioners can play a role in recovery post-social distancing and gives insight on the firsthand experiences of seniors around the country. Journal publication will be pursued after completion of the student's capstone experience. 